\title{
Synthesis of pyrano[4,3-b]quinolizine derivatives from 6-aryl or styryl-4-methylsulfanyl-2-oxo-2H-pyrans and their fluorescence
}

\author{
Masayori Hagimori, ${ }^{a}$ Naoko Mizuyama, ${ }^{\text {and Yoshinori Tominaga }{ }^{*}, \mathrm{~b}}$ \\ ${ }^{a}$ Faculty of Pharmaceutical Sciences of Nagasaki International University, 2825-7, Huis Ten \\ Bosch, Sasebo 859-3298, Japan \\ ${ }^{b}$ Faculty of Environmental Studies of Nagasaki University, 1-14, Bunkyo-machi, Nagasaki 852- \\ 8521, Japan \\ E-mail: ytomi@nagasaki-u.ac.jp
}

\begin{abstract}
New fluorescent compounds 1,11-dihydro-11-imino-1-oxo-3-phenylpyrano[4,3-b]quinolizines were synthesized in good yields by the reaction of 6-aryl-3-cyano-4-methylsulfanyl-2H-pyrones and 4-methylsulfanyl-2,5-dioxo-2,5-dihydro- $1 \mathrm{H}$-pyrrole-3-carbonitrile with 2-pyridylacetates. These fused quinolizine derivatives exhibited fluorescence in solid and solution states.
\end{abstract}

Keywords: Fused 2H-pyrones, pyrano[4,3-b]quinolizine derivatives, fluorescence, intramolecular H-bonding

\section{Introduction}

$2 \mathrm{H}$-Pyrones containing an aryl group at position 6 continue to attract considerable attention in the fields of synthetic and materials chemistry. They are very interesting materials for applications in optoelectronic devices such as displays. ${ }^{1}$ It has been reported that 6-aryl- or styryl-4-methylsulfanyl-2H-pyrones are easily prepared by the reaction of ketene dithioacetal with active methylene compounds like acetophenone in the presence of powdered sodium ${ }^{2}$ and are also useful synthetic intermediates for the synthesis of 6-aryl- and 4-alkoxy- or 4-amino-6styryl-2-oxo-2H-pyran-3-carbonitriles. ${ }^{3,4}$ We report the synthesis of fused $2 \mathrm{H}$-pyrones: pyrano[4,3-b] quinolizine derivatives by the displacement of a 4-methylsulfanyl group in 6-arylor styryl-4-methylsulfanyl-2-oxo-2H-pyrans (1a-d) with 2-pyridylacetonitrile (2a) and methyl 2pyridylacetate (2b) group and detail their fluorescence. 


\section{Results and Discussion}

It has been reported that the reactions of 6-aryl or styryl-4-methylsulfanyl-2-oxo-2 $\mathrm{H}$-pyrans with aryl acetyl compounds yield pyrano[3,4-c]pyridine and pyrano[3,4-c]pyrone derivatives. ${ }^{3 \mathrm{~b}, \mathrm{~d}}$ Although pyrano[3,4-c]pyrone compounds (Type B) do not exhibit fluorescence in solid states, pyrano[3,4-c]pyridine compounds (Type A) having an intramolecular $\mathrm{H}$-bonded structure because of a $\mathrm{C}=\mathrm{O}----\mathrm{H}-\mathrm{O}-\mathrm{C}$ system exhibit strong fluorescence (Figure1). The increase in their fluorescence is attributed to the strong packing caused by the molecular flatness resulting from the intramolecular $\mathrm{H}$-bonded structure of the $\mathrm{C}=\mathrm{O}----\mathrm{H}-\mathrm{O}$ system. This indicates the possibility of the development of fluorescence in other fused $2 \mathrm{H}$-pyrone derivatives with an intramolecular $\mathrm{H}$-bonded structure of the $\mathrm{C}=\mathrm{O}----\mathrm{H}-\mathrm{O}$ system type. Polycyclic pyrone derivatives are expected to exhibit fluorescence and are synthesized by the reaction of 6-aryl or styryl-4-methylsulfanyl2-oxo-2H-pyrans with active methylene compounds.

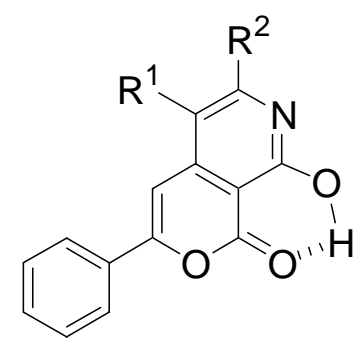

A

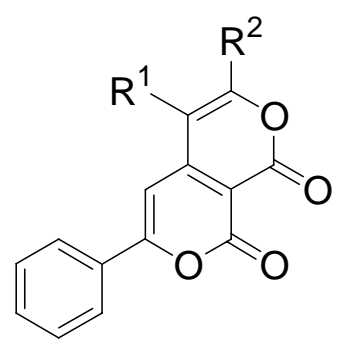

B

\section{Figure 1}

The reaction of compound 1a with 2-pyridylacetonitrile (2a) was conducted in the presence of potassium carbonate as the base and then neutralized with $10 \%$ hydrochloric acid to yield the desired product: 1,11-dihydro-11-imino-1-oxo-3-phenylpyrano[4,3-b]quinolizine-5-carbonitrile (3a) in $84 \%$ yields (Table 1; No. 3a). In a similar manner, compounds $\mathbf{3 b}$ and $\mathbf{3 c}$ were prepared from $\mathbf{1 b}$, $\mathbf{c}$ and $\mathbf{2 a}$ in $84 \%$ and $55 \%$ yields, respectively. Ester compounds $\mathbf{3 d}-\mathbf{g}$ were synthesized from 1a-d and $\mathbf{2 b}$ in a manner similar to that described for the synthesis of 3a. In this case, the products were precipitates that appeared from a basic solution of the reaction mixture. The yields were also good, being $95 \%, 72 \%, 53 \%$, and $55 \%$, respectively. 
Table 1. Reaction of $2 H$-pyrones (1a-d) with active methylene compounds $(\mathbf{2 a}$, b) in the presence of a base

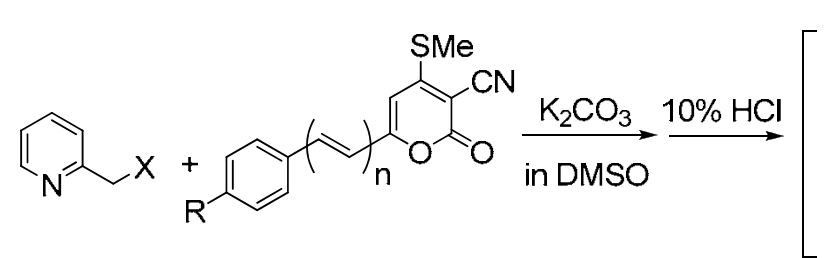

$2 a, b$

1a-d

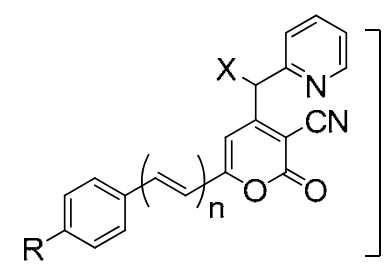

3'a-g<smiles>[R]c1ccc(/C=C/C([2H])([2H])C=Cc2cc3c([X])c4ccccn4c(=N)c3c(=O)o2)cc1</smiles>

$3 a-9$

\begin{tabular}{llllccl}
\hline No. & $\mathrm{R}$ & $\mathrm{X}$ & $\mathrm{n}$ & Yield \% & $\mathrm{mp}$ & Appearance \\
\hline 3a & $\mathrm{H}$ & $\mathrm{CN}$ & 0 & 84 & $320-322^{\circ}$ & yellow crystal \\
3b & $\mathrm{OMe}$ & $\mathrm{CN}$ & 0 & 84 & $280-282^{\circ}$ & orange needle \\
3c & $\mathrm{NMe}_{2}$ & $\mathrm{CN}$ & 0 & 55 & $247-249^{\circ}$ & red needle \\
3d & $\mathrm{H}$ & $\mathrm{COOMe}$ & 0 & 95 & $215-218^{\circ}$ & orange needle \\
3e & $\mathrm{OMe}$ & $\mathrm{COOMe}$ & 0 & 72 & $244-245^{\circ}$ & orange needle \\
3f & $\mathrm{NMe}_{2}$ & CoOMe & 0 & 53 & $260-262^{\circ}$ & orange needle \\
3g & $\mathrm{NMe}_{2}$ & CoOMe & 1 & 55 & $248-250^{\circ}$ & dark red needle \\
\hline
\end{tabular}

Dicarbonyl derivatives (4a, b) were synthesized via the reaction of $\mathbf{2 b}$ with methyl 4methanesulfinyl-2-oxo-6-phenyl-2H-pyran-3-carboxylate (1e, f) in the presence of potassium carbonate in DMSO. Decarboxylated derivatives (5a, b) were also obtained via $\mathbf{4 a}$ and $\mathbf{4 b}$ treated with polyphospholic acid (PPA) in $84 \%$ and $88 \%$ yields, respectively (Table 2 ). 
Table 2. Reaction of $2 \mathrm{H}$-pyrones (1e, f) with active methylene compound (2b) in the presence of a base

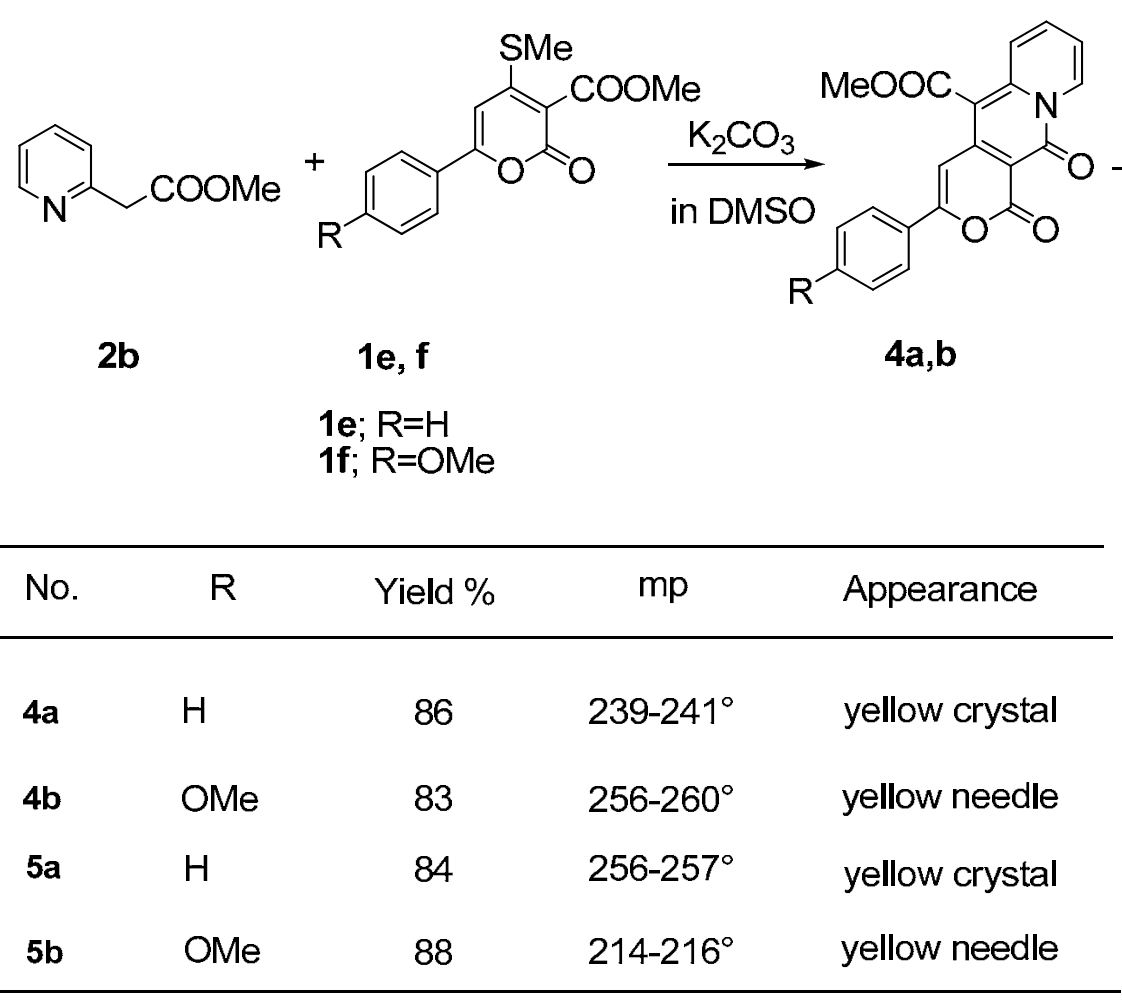

The UV-vis absorption and fluorescence emission spectra of $\mathbf{3 a -} \mathbf{a}, \mathbf{4 a}, \mathbf{b}$, and $\mathbf{5 a}$, $\mathbf{b}$ were analyzed in solution (dichloromethane and ethanol) and solid states, respectively, at room temperature. The spectroscopic properties - absorption maxima $\left(\lambda_{\max }\right)$, molar absorptivities $(\varepsilon)$, fluorescence maxima (Em max), and relative fluorescent intensities (RI) — are listed in Table 3. In solid states, the RI was measured against the standard of $\mathrm{Alq}_{3}[\operatorname{tris}(8-$ hydroxyquinolinato)aluminum.$^{5}$ 
Table 3. UV and fluorescence spectra of pyrano[4,3-b]quinolizine derivatives in dichloromethane and in solid states

\begin{tabular}{|c|c|c|c|c|c|c|c|c|c|}
\hline No. & $\begin{array}{c}\text { Max } \\
(\log \mathrm{e})^{\mathrm{a}} \\
\mathrm{nm} \\
\text { EtOH }\end{array}$ & $\begin{array}{l}\mathrm{Ex}(\mathrm{nm}) \\
\mathrm{CH}_{2} \mathrm{CL}_{2}\end{array}$ & $\begin{array}{l}\mathrm{Em}(\mathrm{nm}) \\
\mathrm{CH}_{2} \mathrm{CL}_{2}\end{array}$ & $\mathrm{SS}^{\mathrm{b}}$ & $\begin{array}{c}\text { Ex(nm) } \\
\text { Solid }\end{array}$ & $\begin{array}{c}\text { Em(nm) } \\
\text { Solid }\end{array}$ & $\Delta \mathrm{F}^{\mathrm{c}}$ & $\mathrm{SS}^{\mathrm{d}}$ & $\mathrm{RI}^{\mathrm{e}}$ \\
\hline $3 a$ & $\begin{array}{c}350 \\
(3.75)\end{array}$ & 356 & 399 & 143 & 348 & 553 & 54 & 205 & 0.07 \\
\hline $3 b$ & $\begin{array}{c}368 \\
(3.99)\end{array}$ & 372 & 497 & 125 & 342 & 549 & 52 & 207 & 0.06 \\
\hline $3 c$ & $\begin{array}{c}456 \\
(4.08) \\
\end{array}$ & - & - & - & 338 & 565 & - & 227 & 0.03 \\
\hline $3 d$ & $\begin{array}{c}296 \\
(4.52)\end{array}$ & 325 & 486 & 161 & 343 & 560 & 74 & 217 & 0.02 \\
\hline $3 \mathrm{e}$ & $\begin{array}{c}273 \\
(4.34) \\
\end{array}$ & 346 & 512 & 26 & 343 & 562 & 50 & 219 & 0.01 \\
\hline $3 \mathrm{f}$ & $\begin{array}{c}459 \\
(4.21) \\
\end{array}$ & 486 & 512 & 26 & 343 & 562 & 50 & 219 & 0.01 \\
\hline $3 g$ & $\begin{array}{c}270 \\
(4.46) \\
\end{array}$ & - & - & - & - & - & - & - & - \\
\hline $4 \mathrm{a}$ & $\begin{array}{c}429 \\
(4.44)\end{array}$ & 439 & 477 & 38 & 342 & 518 & 41 & 176 & 0.43 \\
\hline $4 \mathrm{~b}$ & $\begin{array}{c}371 \\
(4.47)\end{array}$ & 440 & 480 & 40 & 345 & 524 & 44 & 179 & 0.27 \\
\hline $5 \mathrm{a}$ & $\begin{array}{c}443 \\
(4.52) \\
\end{array}$ & 447 & 482 & 35 & 345 & 546 & 64 & 201 & 0.17 \\
\hline $5 b$ & $\begin{array}{c}445 \\
(4.46) \\
\end{array}$ & 427 & 455 & 28 & 335 & 539 & 84 & 204 & 0.02 \\
\hline
\end{tabular}

${ }^{a}$ Measurement in ethanol.

${ }^{\mathrm{b}}$ Stokes Shift, Em-Ex in solution.

${ }^{\mathrm{c}} \Delta \mathrm{F}=\mathrm{Em}$ (solid)-Em(solution).

${ }^{\mathrm{d}}$ Stokes Shift, Em-Ex in solid states.

${ }^{\mathrm{e}}$ Relative intensity of fluorescence in solid states, using $\mathrm{Alq}_{3}$ as the standard compound.

The Em max of 3a-f ranged from 486-512 $\mathrm{nm}$ in dichloromethane, except for 3c, and 549-565 $\mathrm{nm}$ in solid states. Compared with $2 \mathrm{H}$-pyrones $(\mathbf{1 a}-\mathbf{c}), 3 \mathbf{a}, \mathbf{b}, \mathbf{d}$, and e exhibited bathochromical shifts near the red fluorescent compounds in solid states. In ethanol, these compounds did not emit any light. With regard to Em max and RI, the obvious substitution effects at position 5 of 
the pyrano[4,3-b]quinolizine ring and position 4 of the aryl ring were not observed. The $\varepsilon$ values of these compounds were almost equal to those of their precursors. The 6-(4dimethylamino)styryl compound (3g) was dark red in color; however, it did not exhibit fluorescence in the solution or solid state. In dichloromethane, 3a, b, d, and $\mathbf{e}$ exhibited significantly larger Stokes shifts (SS), indicating that the $\mathrm{S}_{1}$ states of these compounds are stabilized by a solvent polarization field.

Fused pyrones - dicarbonyl derivatives $\mathbf{4 a}$, $\mathbf{b}$ and decarboxylated derivatives $\mathbf{5 a}$, b-were also analyzed for fluorescent emissions. The Em max of $\mathbf{4 a}$, b exhibited hypsochromic shifts compared with 3d, $\mathbf{e}$ in dichloromethane and solid states. The RIs of $\mathbf{4 a}, \mathbf{b}$ were stronger than those of 3d, $\mathbf{e}$ in solid states. This suggested that a change in the structure at position 11 of the pyrano[4,3-b]quinolizine ring influenced both the Em max and RI. However, the light emitting region of $\mathbf{5 a} \mathbf{a} \mathbf{b}$ shifted upward by approximately $20 \mathrm{~nm}$ compared with that of $\mathbf{4 a}, \mathbf{b}$ in solid states, and the RIs of $\mathbf{5 a}, \mathbf{b}$ were weaker than those of $\mathbf{4 a ,} \mathbf{b}$ in solid states, indicating that the substitution effects on the Em max and RI occurred because of the introduction of a carboxyl group at position 5 of the pyrano[4,3-b]quinolizine ring. The substitution effect at the position 4 of the aryl ring was not observed. In ethanol, $\mathbf{4 a}, \mathbf{b}$ and $\mathbf{5 a} \mathbf{a} \mathbf{b}$ also did not emit any light, as was the case with 3a-f. The F value, the difference between the Em values in the solid and solution states, varied from $41 \mathrm{~nm}$ to $84 \mathrm{~nm}$ in all compounds.

As expected, polycyclic pyrone derivatives with an intramolecular H-bonded structure resulting from a $\mathrm{C}=\mathrm{N}-\mathrm{H}----\mathrm{O}=\mathrm{C}$ system exhibited fluorescence. Some of them emitted a greater bathochromical shift than the pyrone derivatives used as precursors. However, polycyclic pyrone derivatives without an intramolecular $\mathrm{H}$-bonded structure also exhibited fluorescence. As a result, it is considered that the optimal structures for emitting between pyrone and polycyclic pyrone derivatives have great differences. From our earlier study, the flatness of the structure resulting from a $\mathrm{C}=\mathrm{O}----\mathrm{H}-\mathrm{O}-\mathrm{C}$ system appears to influence both the Em max and RI in pyrone derivatives; whereas, it does not necessarily influence them in polycyclic pyrone derivatives. Moreover, with respect to the substitution effect, the introduction of electro-donating or electrowithdrawing groups influences the emissions of pyrone derivatives, whereas their contribution is very low in polycyclic pyrone derivatives with the intramolecular H-bonded structure due to a $\mathrm{C}=\mathrm{N}-\mathrm{H}----\mathrm{O}=\mathrm{C}$ system. On the other hand, polycyclic pyrone derivatives without the intramolecular H-bonded structure are influenced by the substitution effect. Research regarding this effect is currently being conducted.

\section{Conclusions}

In summary, fused pyrones 1,11-dihydro-11-imino-1-oxo-3-phenylpyrano[4,3-b]quinolizines, which are easily prepared by the reaction of 6-aryl-4-methylsulfanyl-2-oxo- $2 \mathrm{H}$-pyran-3carbonitriles with active methylene compounds such as 2-pyridylacetonitrile or pyridylacetates in 
the presence of potassium carbonate, exhibit fluorescence in the solid state. This is the first report of fluorescence in fused aryl-2H -pyrone derivatives.

\section{Experimental Section}

General Procedures. Identifications of compounds and measurements of properties were carried out by general procedures using the following equipment. All melting points were determined in a capillary tube and uncorrected. Infrared (IR) spectra were recorded in potassium bromide pellets on JASCO 810 or Shimazu IR-460 spectrometer and ultraviolets (UV) absorption spectra were determined in $95 \%$ ethanol on a Hitachi 323 spectrometer. Fluorescence spectra were determined on Shimazu RF-5300. Nuclear magnetic resonance (NMR) spectra were obtained on Gemini 300NMR(300MHz), 500NMR(500MHz) and a JEOL-GX-400 (400MHz) spectrometers with tetramethylsilane as an internal standard. Mass spectra (MS) were recorded on JOEL DX303 and JMS-T100LP mass spectrometers. Microanalyses were performed on a Perkin Elmer 2002 at Nagasaki University. All chemicals were reagent grade and used without further purification unless otherwise specified.

\section{Method of Measurement of Fluorescence}

(a) In the solid state. A powder sample of subject compound is heaped in the tray. After covering the sample with quartz plate, this part was fixed in fluorescence spectrometer. After fixing the fluorescent wavelength, the excitation spectrum was determined by the scanning with the fluorescent wavelength. Similarly, fluorescent spectrum was obtained after scanning with the excitation wavelength. After obtaining these results, the excitation wavelength was decided and the fluorescence spectrum was measured. The fluorescent relative intensity was determined by using $\mathrm{Alq}_{3}$ as standard sample. Fluorescence of standard sample and all subject compounds were measured on $345 \mathrm{~nm}$ excitation.

(b) In solution. The concentration of measuring samples in the excitation wavelength region was adjusted under 0.05 on the molar absorption.

1,11-Dihydro-11-imino-1-oxo-3-phenylpyrano[4,3-b]quinolizine-5-carbonitrile (3a). A mixture of $0.109 \mathrm{~g}(0.45 \mathrm{mmoles})$ of $1 \mathrm{a}, 0.053 \mathrm{~g}$ ( $0.45 \mathrm{mmoles})$ of 2-pyridylacetonitrile (2a), and $0.124 \mathrm{~g}$ ( 0.9 mmoles) of potassium carbonate in $10 \mathrm{ml}$ of DMSO was stirred for 2 hours at room temperature. This mixture was stirred and heated for $30 \mathrm{~min}$ at $50-60^{\circ} \mathrm{C}$. The reaction mixture was poured into $200 \mathrm{ml}$ of ice-water and acidified with $10 \%$ hydrochloric acid. The precipitate that appeared was collected by filtration, washed with water, and recrystallized from dimethyl formamide (DMF) to give $0.120 \mathrm{~g}(0.38$ mmoles, $84 \%$ yield $)$ of yellow crystals, mp $320-322^{\circ} \mathrm{C}$. IR $\left(\mathrm{KBr}, \mathrm{cm}^{-1}\right): 2370,2210(\mathrm{CN}), 1710(\mathrm{CO}), 1620,1600,1520,1480,1050,780$. UV (EtOH) $\lambda$ nm (log ع): 250 (3.58), 260 (3.57), 294 (3.60), 350 (3.75), 457 (3.43), 479 (3.45). Fluoresence (solid): Ex, $348 \mathrm{~nm}$; Em, $553 \mathrm{~nm}$; RI 0.07. ${ }^{1} \mathrm{H}$ NMR $\left(\mathrm{CDCl}_{3}\right)$ 8: $7.04(1 \mathrm{H}, \mathrm{s} 4-\mathrm{H}), 7.18(1 \mathrm{H}, \mathrm{m}, 8-$ $\mathrm{H}), 7.49-7.51(3 \mathrm{H}, \mathrm{m}$, phenyl-H), 7.82-7.88 (2H, m, 6-H, 7-H), 7.94-7.98 (2H, m, phenyl-H), 
$9.74(1 \mathrm{H}, \mathrm{d}, J 6.6 \mathrm{~Hz}, 9-\mathrm{H}), 10.51(1 \mathrm{H}, \mathrm{s}, \mathrm{N}-\mathrm{H}) .{ }^{13} \mathrm{C}-\mathrm{NMR}\left(100 \mathrm{MHz}, \mathrm{CDCl}_{3}\right) \delta: 95.50,98.25$, $116.25,116.33,122.86,126.22,129.07,130.61,131.77,131.79,138.85,146.34,148.64,151.84$, 160.65, 160.95. Ms:m/z $314\left(\mathrm{M}^{+}+1,40\right), 313\left(\mathrm{M}^{+}, 100\right), 236$ (12), 229 (11), 208 (23), 105 (54), 77 (18), 105 (81). Anal. Calcd for $\mathrm{C}_{19} \mathrm{H}_{11} \mathrm{~N}_{3} \mathrm{O}_{2}$ 313.09: C, 72.84; H, 3.54; N, 13.41. Found. C, $72.69 ; \mathrm{H}, 3.58 ; \mathrm{N}, 13.51$.

\section{1,11-Dihydro-1-imino-3-(4-methoxyphenyl)-1-oxopyrano[4,3-b]quinolizine-5-carbonitrile}

(3b). This compound ( $0.576 \mathrm{~g}, 0.168 \mathrm{mmoles})$ was prepared in $84 \%$ yield from $0.546 \mathrm{~g}(2.0$ mmoles) of $\mathbf{1 b}$ and $0.354 \mathrm{~g}$ (3.0 mmoles) of $\mathbf{2 a}$ in a manner similar to that described for the synthesis of 3a. An analytical sample was recrystallized from DMF to give orange needles, mp 280-282 ${ }^{\circ} \mathrm{C}$. IR (KBr, cm $\left.{ }^{-1}\right): 3280(\mathrm{NH}), 2190(\mathrm{CN}), 1690,1580,1505,1478,1180,1018$. UV (EtOH) $\lambda$ nm (log $\varepsilon): 318$ (3.98), 368 (3.99), 451 (3.75). Fluoresence (solid): Ex, 342 nm; Em, 549 nm; RI 0.06. ${ }^{1} \mathrm{H}$ NMR $\left(\mathrm{CDCl}_{3}\right) \delta: 3.90(3 \mathrm{H}, \mathrm{s}, \mathrm{OMe}), 6.91(1 \mathrm{H}, \mathrm{s}, 4-\mathrm{H}), 7.01(1 \mathrm{H}, \mathrm{d}, J 9.0$ Hz, 3', 5'-H), 7.16 (1H, m, 7-H), 7.82 (1H, m, 8-H), 7.91 (2H, d, J 9.0 Hz, 2', 6'-H), 9.13 (1H, d,

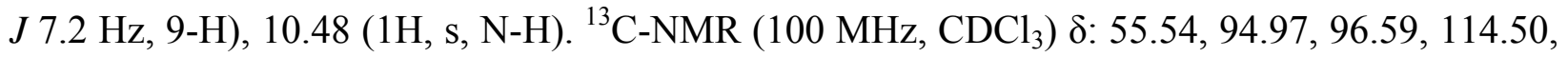
115.97, 116.48, 122.78, 122.99, 128.05, 131.69, 138.68, 146.54, 148.65, 151.90, 160.75, 161.08, 162.612. Ms:m/z $344\left(\mathrm{M}^{+}+1,25\right), 343\left(\mathrm{M}^{+}, 100\right), 342$ (12), 315 (12), 208 (13), 135 (77), 77 (11). Anal. Calcd. for $\mathrm{C}_{20} \mathrm{H}_{13} \mathrm{~N}_{3} \mathrm{O}_{3}$ 343.34: C, 69.96; H, 3.82; N, 12.24. Found: C, 69.96; H, 3.78; N, 12.20.

\section{1,11-Dihydro-3-(4-dimethylaminophenyl)-11-imino-1-oxopyrano[4,3-b]quinolizine-5-}

carbonitrile (3c). This compound ( $0.426 \mathrm{~g}, 1.2 \mathrm{mmoles})$ was prepared in $55 \%$ yield from $0.573 \mathrm{~g}$ ( 2.0 mmoles) of 1c and $0.236 \mathrm{~g}$ ( 2.0 mmoles) of $\mathbf{2 a}$ in a manner similar to that described for the synthesis of 3a. An analytical sample was recrystallized from DMF to give red needles, mp 247$249^{\circ} \mathrm{C}$. IR (KBr, cm $\left.{ }^{-1}\right): 3450(\mathrm{NH}), 2190(\mathrm{CN}), 1700,1580,1510,1380,1200,870$. UV (EtOH) $\lambda \mathrm{nm}(\log \varepsilon): 385$ (3.92), 456 (4.07). Fluoresence (solid): Ex, $338 \mathrm{~nm}$; Em, $565 \mathrm{~nm}$; RI 0.03. ${ }^{1} \mathrm{H}$ NMR $\left(\mathrm{CDCl}_{3}\right) \delta: 3.08$ (3H, s, NMe), 3.10 (3H, s, NMe), $6.74(2 \mathrm{H}, \mathrm{d}, J 9.0 \mathrm{~Hz}, 3$ ', 5'-H), 6.82 (1H, s, 4-H), 7.07 (1H, m, 8-H), 7.75-7.80 (2H, m, 6, 7-H), 7.84 (2H, d, J 9.0 Hz, 2', 6'-H), 9.67 $(1 \mathrm{H}, \mathrm{d}, J 7.2 \mathrm{~Hz}, 9-\mathrm{H}) .{ }^{13} \mathrm{C}-\mathrm{NMR}\left(100 \mathrm{MHz}, \mathrm{CDCl}_{3}\right) \delta: 40.06,94.31,94.55,111.56,115.44$, $116.77,117.25,122.65,127.86,131.56,138.29,146.74,148.69,152.11,152.58,161.47,161.81$. Ms:m/z $357\left(\mathrm{M}^{+}+1,22\right), 356\left(\mathrm{M}^{+}, 100\right), 355$ (12), 328 (10), 148 (65), 44 (30). Anal. Calcd. for $\mathrm{C}_{21} \mathrm{H}_{16} \mathrm{~N}_{4} \mathrm{O}_{2}$ 356.13: C, 70.77; H, 4.53; N, 15.72. Found: C, 70.78; H, 4.56; N, 15.70.

Methyl 1,11-dihydro-11-imino-1-oxo-3-phenylpyrano[4,3-b]quinolizine-5-carboxylate (3d). This compound ( $0.658 \mathrm{~g}, 1.9$ mmoles $)$ was prepared in $95 \%$ yield from $0.482 \mathrm{~g}$ ( $2.0 \mathrm{mmoles})$ of $\mathbf{1 a}$ and $0.302 \mathrm{~g}$ ( $2.0 \mathrm{mmoles})$ of $\mathbf{2} \mathbf{b}$ in a manner similar to that described for the synthesis of $3 \mathbf{a}$. An analytical sample was recrystallized from DMF to give orange needles, mp $215-218^{\circ} \mathrm{C}$. IR $\left(\mathrm{KBr}, \mathrm{cm}^{-1}\right): 3265(\mathrm{NH}), 1650,1590,1510,1478,1320,758$. UV (EtOH) $\lambda \mathrm{nm}(\log \varepsilon): 296$ (4.52), 351 (4.50), 479 (4.28). Fluoresence (solid): Ex, 343 nm; Em,560 nm; RI 0.02. ${ }^{1} \mathrm{H}$ NMR $\left(\mathrm{CDCl}_{3}\right) \delta: 4.02(3 \mathrm{H}, \mathrm{s}, \mathrm{OMe}), 7.08(1 \mathrm{H}, \mathrm{dd}, J 6.6,7.2 \mathrm{~Hz}, 8-\mathrm{H}), 7.37(1 \mathrm{H}, \mathrm{s} 4-\mathrm{H}), 7.40-7.52$ (3H, m, phenyl-H), 7.65 (1H, dd, J 7.2, 8.7 Hz, 7-H), 7.88-7.94 (2H, m, phenyl-H), 8.09 (1H, d, $J 8.7 \mathrm{~Hz}, 6-\mathrm{H}), 9.75(1 \mathrm{H}, \mathrm{d}, J 6.6 \mathrm{~Hz}, 9-\mathrm{H}), 10.48\left(1 \mathrm{H}\right.$, br s, NH). ${ }^{13} \mathrm{C}-\mathrm{NMR}\left(100 \mathrm{MHz}, \mathrm{CDCl}_{3}\right)$ $\delta: 52.10,95.30,97.06,98.99,115.36,123.40,125.90,128.86,129.03,131.25,131.40,136.75$, 
144.48, 146.85, 152.81, 158.18, 162.02, 166.61. Ms:m/z $347\left(\mathrm{M}^{+}+1,22\right), 346\left(\mathrm{M}^{+}, 100\right)$, 288(12), 287(41), 259(16), 258(15), 137(15), 121(20), 105(20). Anal. Calcd. for $\mathrm{C}_{20} \mathrm{H}_{14} \mathrm{~N}_{2} \mathrm{O}_{4}$ 346.10: C, 69.36; H, 4.07; N, 8.09. Found: C, 69.55; H, 3.98; N, 8.08.

Methyl 1,11-dihydro-11-imino-3-(4-methoxyphenyl)-1-oxopyrano[4,3-b]quinolizine-5carboxylate (3e). This compound (0.542 g, 1.44 mmoles) was prepared in $72 \%$ yield from $0.546 \mathrm{~g}$ ( $2.0 \mathrm{mmoles})$ of $\mathbf{1 b}$ and $0.302 \mathrm{~g}$ ( $2.0 \mathrm{mmoles})$ of $\mathbf{2} \mathbf{b}$ in a manner similar to that described for the synthesis of 3a. An analytical sample was recrystallized from DMF to give orange needles, mp $244-245^{\circ} \mathrm{C}$. IR $\left(\mathrm{KBr}, \mathrm{cm}^{-1}\right): 1700$ (CO), 1629, 1598, 1514, 820. UV (EtOH) $\lambda \mathrm{nm}$ (log ع): 477 (4.10), 366 (4.32), 328 (4.19) 273 (4.34). Fluoresence (solid): Ex, 343 nm; Em, 562 nm; RI 0.07. ${ }^{1} \mathrm{H}$ NMR $\left(\mathrm{CDCl}_{3}\right) \delta: 3.90(3 \mathrm{H}, \mathrm{s}, \mathrm{OMe}), 4.00(3 \mathrm{H}, \mathrm{s}, \mathrm{OMe}), 6.99(2 \mathrm{H}, \mathrm{d}, \mathrm{J} 9.1 \mathrm{~Hz}$, 3' 5'-H), 7.03 (1H, dd, J 6.6, 6.6 Hz, 8-H), 7.26 (1H, s, 4-H), 7.62 (1H, ddd, J 1.5, 6.6, 9.1 Hz, 7H), 7.85 (2H, d, J 9.1 Hz, 2', 6'-H), 8.05 (1H, dd, J 1.5, 9.1 Hz, 6-H), 9.72 (1H, d J 6.6 Hz, 9-H), $10.38\left(1 \mathrm{H}\right.$, br s, NH). ${ }^{13} \mathrm{C}-\mathrm{NMR}\left(100 \mathrm{MHz}, \mathrm{CDCl}_{3}\right) \delta: 52.05,55.45,94.96,96.73,97.43,114.28$, $115.01,123.32,123.90,127.65,131.18,136.55,144.81,146.90,152.93,158.35,161.94,162.19$, 166.79. Ms:m/z 377 (M+1, 22), $376\left(\mathrm{M}^{+}, 100\right), 347$ (11), 346 (35), 317 (34), 316 (10), 288 (12), 135 (47), 91 (21). Anal. Calcd. for $\mathrm{C}_{20} \mathrm{H}_{14} \mathrm{~N}_{2} \mathrm{O}_{4}$ 376.11: C, 67.02; H, 4.28; N, 7.44. Found: C, $66.83 ; \mathrm{H}, 4.20 ; \mathrm{N}, 7.32$.

Methyl 1,11-dihydro-3-(4-dimethylaminophenyl)-11-imino-1-oxoyrano[4,3-b]quinolizine-5carboxylate (3f). This compound $(0.414 \mathrm{~g}, 1.06 \mathrm{mmoles})$ was prepared in 53\% yield from $0.568 \mathrm{~g}$ ( $2.0 \mathrm{mmoles})$ of $\mathbf{1 c}$ and $0.302 \mathrm{~g}$ ( $2.0 \mathrm{mmoles})$ of $\mathbf{2 b}$ in a manner similar to that described for the synthesis of 3a. An analytical sample was recrystallized from DMF to give orange needles, mp 260-262 ${ }^{\circ} \mathrm{C}$. IR (KBr, cm $\left.{ }^{-1}\right): 1710$ (CO), 1584, 1512, 1380, 1320, 810. UV (EtOH) $\lambda$ nm (log ع): 459 (4.21), 379 (4.09). Fluoresence (solid): Ex, 343 nm; Em, $562 \mathrm{~nm}$; RI 0.01. ${ }^{1} \mathrm{H}$

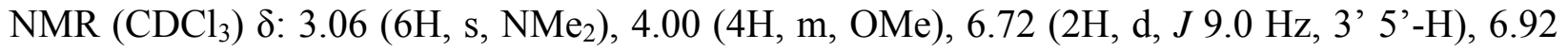
$(1 \mathrm{H}, \mathrm{m}, 8-\mathrm{H}), 7.15$ (1H, s, 4-H), $7.54(1 \mathrm{H}, \mathrm{m}, 7-\mathrm{H}), 7.77$ (2H, d, J $9.0 \mathrm{~Hz}, 2$ ' 6'-H), 8.00 (1H, d, J $9.6 \mathrm{~Hz}, 6-\mathrm{H}), 9.67(1 \mathrm{H}, \mathrm{d}, J 7.8 \mathrm{~Hz}, 9-\mathrm{H}), 10.34(1 \mathrm{H}, \mathrm{s}, \mathrm{NH}) .{ }^{13} \mathrm{C}-\mathrm{NMR}\left(100 \mathrm{MHz}, \mathrm{CDCl}_{3}\right) \delta$ : 40.07, 51.96, 94.51, 95.52, 96.63, 111.54, 114.53, 123.16, 127.41, 131.06, 136.20, 145.09, 146.80, 152.07, 153.10, 159.46, 162.51, 166.99. Ms:m/z $390\left(\mathrm{M}^{+}+1,21\right), 389\left(\mathrm{M}^{+}, 100\right), 357$ (13), 330 (12), 329 (11), 148 (83). Anal. Calcd. for $\mathrm{C}_{22} \mathrm{H}_{19} \mathrm{~N}_{3} \mathrm{O}_{4}$ 389.14: C, 67.86; H, 4.92; N, 10.79. Found: C, 67.94; H, 4.92; N, 10.82 .

Methyl 1,11-dihydro-3-(4-dimethylamino-styryl)- 11-imino-1-oxoyrano[4,3-b]quinolizine-5carboxylate (3g). This compound $(0.457 \mathrm{~g}, 1.1 \mathrm{mmoles})$ was prepared in $55 \%$ yield from $0.624 \mathrm{~g}$ ( 2.0 mmoles) of $\mathbf{1 d}$ and $0.302 \mathrm{~g}$ ( $2.0 \mathrm{mmoles})$ of $\mathbf{2} \mathbf{b}$ in a manner similar to that described for the synthesis of 3a. An analytical sample was recrystallized from DMF to give dark red needles, mp 248-250 ${ }^{\circ} \mathrm{C}$. IR (KBr, cm ${ }^{-1}$ ): 3423 (br, NH), 1720 (CO), 1697 (CO), 1583, 158, 1182. UV $(\mathrm{EtOH}) \lambda \mathrm{nm}(\log \varepsilon): 270$ (4.46), 472 (4.03), 500 (4.03). Fluoresence (solid): no fluorescence. ${ }^{1} \mathrm{H}$ NMR $\left(\mathrm{CDCl}_{3}\right) \delta: 3.01$ (3H, s, NMe), $3.02(3 \mathrm{H}, \mathrm{s}, \mathrm{NMe}), 3.98(3 \mathrm{H}, \mathrm{s}, \mathrm{OMe}), 6.47$ (2H, d, J 15.6 $\mathrm{Hz}, \mathrm{C}=\mathrm{CH}), 6.69$ (2H, d, J 8.7 Hz, 3' 5'-H), $6.88(1 \mathrm{H}, \mathrm{s}, 4-\mathrm{H}), 6.97(1 \mathrm{H} \mathrm{m}, 8-\mathrm{H}), 7.43$ (2H, d, $J$ $\left.8.7 \mathrm{~Hz}, 2^{\prime}, 6^{\prime}-\mathrm{H}\right), 7.48(2 \mathrm{H}, \mathrm{d}, J 15.6 \mathrm{~Hz}, \mathrm{C}=\mathrm{CH}), 8.00(1 \mathrm{H}, \mathrm{d}, J 9.3 \mathrm{~Hz}, 6-\mathrm{H}), 9.68(1 \mathrm{H}, \mathrm{d} J 7.2$ $\mathrm{Hz}, 9-\mathrm{H}), 10.33(1 \mathrm{H}, \mathrm{s}, \mathrm{NH}) .{ }^{13} \mathrm{C}-\mathrm{NMR}\left(100 \mathrm{MHz}, \mathrm{CDCl}_{3}\right) \delta: 40.13,52.15,94.73,100.92$, 
111.92, 114.06, 114.98, 123.16, 123.21, 129.18, 131.21, 136.29, 136.80, 144.62, 151.23, 152.88, 158.51, 162.11, 166.70. Ms:m/z $416\left(\mathrm{M}^{+}+1,27\right), 415\left(\mathrm{M}^{+}, 100\right), 400$ (32), 383 (27), 312 (11), 174 (44), 146 (18), 44 (52). Anal. Calcd for $\mathrm{C}_{24} \mathrm{H}_{21} \mathrm{~N}_{3} \mathrm{O}_{4}$ 415.4414: C, 69.39; H, 5.10; N, 10.11. Found C, 69.32; H, 5.01; N, 9.99.

Methyl 1,11-dihydro-1,11-dioxo-3-phenylyrano[4,3-b]quinolizine-5-carboxylate (4a). A mixture of $0.552 \mathrm{~g}$ (2.0 mmoles) of 1e, $0.453 \mathrm{~g}$ (3.0 mmoles) of methyl 2-pyridylacetate (2b), and $0.665 \mathrm{~g}$ (5.0 mmoles) of potassium carbonate in $20 \mathrm{ml}$ of DMSO was stirred for 2 hours at room temperature. This mixture was stirred and heated for $20 \mathrm{~min}$ at $50-60^{\circ} \mathrm{C}$. The reaction mixture was poured into $200 \mathrm{ml}$ of ice-water. The precipitate that appeared was collected by filtration, washed with water, and recrystallized from dimethyl formamide (DMF) to give 0.594 $\mathrm{g}\left(1.71 \mathrm{mmoles}, 86 \%\right.$ yield) of yellow crystals, mp $239-241^{\circ} \mathrm{C}$. IR $\left(\mathrm{KBr}, \mathrm{cm}^{-1}\right): 1735(\mathrm{CO})$, 1701 (CO), 1626, 1522, 1451, 1159. UV (EtOH) $\lambda \mathrm{nm}(\log \varepsilon): 408$ (4.35), 429 (4.44). Fluoresence (solid): Ex, $342 \mathrm{~nm}$; Em, $518 \mathrm{~nm}$; RI 0.43. ${ }^{1} \mathrm{H}$ NMR $\left(\mathrm{CDCl}_{3}\right) \delta: 4.08$ (3H, s, OMe), $7.21(1 \mathrm{H}, \mathrm{s} 4-\mathrm{H}), 7.24(1 \mathrm{H}, \mathrm{m}, 8-\mathrm{H}), 7.48$ (3H, m, phenyl-H), $7.74(1 \mathrm{H}, \mathrm{m}, 7-\mathrm{H}), 7.91$ (2H, m, phenyl-H), 8.09 (1H, d, J 8.8 Hz, 6-H), 9.39 (1H d, J $5.8 \mathrm{~Hz}, 9-\mathrm{H}) .{ }^{13} \mathrm{C}-\mathrm{NMR}\left(100 \mathrm{MHz}, \mathrm{CDCl}_{3}\right)$ $\delta: 52.63,96.70,97.90,101.16,116.20,123.70,126.22,128.87,130.13,131.31,131.36,136.52$, 145.74, 146.29, 154.90, 158.56, 159.58, 166.32, 175.06. Ms:m/z $348\left(\mathrm{M}^{+}+1,26\right), 347\left(\mathrm{M}^{+}, 100\right)$, 320 (13), 319 (65), 316 (34), 291 (16), 288 (22), 261 (15), 242 (14), 233 (11), 232 (12), 204 (25), 203 (12), 105 (36), 77 (19). HRMS (ESI) calcd for $\mathrm{C}_{20} \mathrm{H}_{13} \mathrm{NO}_{5}, \mathrm{~m} / \mathrm{z} 347.0794\left(\mathrm{M}^{+}\right.$); found, $\mathrm{m} /$ z 347.0793 .

Methyl 1,11-dihydro-3-(4-methoxy)phenyl-1,11-dioxoyrano[4,3-b]quinolizine-5-carboxylate (4b). This compound $(0.312 \mathrm{~g}, 0.828 \mathrm{mmoles})$ was prepared in $83 \%$ yield from $0.306 \mathrm{~g}(1.0$ mmoles) of $\mathbf{1 f}$ and $0.221 \mathrm{~g}$ (1.46 mmoles) of $\mathbf{2 b}$ in a manner similar to that described for the synthesis of 4a. An analytical sample was recrystallized from DMF to give yellow needles, $\mathrm{mp}$ 256-260 ${ }^{\circ}$. IR (KBr, cm $\left.{ }^{-1}\right): 1715$ (CO), 1678 (CO), 1602, 1510, 1470, 1258, 1178, 1135. UV (EtOH) $\lambda$ nm (log $\varepsilon): 431$ (4.29), 371 (4.47). Fluoresence (solid): Ex, 345 nm; Em, 524 nm; RI 0.27. ${ }^{1} \mathrm{H}$ NMR $\left(\mathrm{CDCl}_{3}\right) \delta: 3.88$ (3H, s, OMe), 4.07 (3H, s, OMe), 7.00 (2H, m, 3', 5'-H), 7.13 (1H, s 4-H), 7.17 (1H, m, 8-H), 7.70 (1H, m, 7-H), 7.86 (1H, m, 2', 6’-H), 8.06 (1H, d, J 8.8 Hz, 6-H), 9.39 (1H d, J 7.3 Hz, 9-H). ${ }^{13} \mathrm{C}-\mathrm{NMR}\left(100 \mathrm{MHz}, \mathrm{CDCl}_{3}\right) \delta: 52.57,55.55,96.27,100.93$, $114.29,115.88,123.58,128.01,128.36,130.07,136.32,145.71,146.59,154.96,158.72,159.71$, 162.23, 166.44. Ms:m/z $378\left(\mathrm{M}^{+}+1,23\right), 377\left(\mathrm{M}^{+}, 100\right), 349$ (30), 346 (20), 321 (28), 306 (12), 278 (11), 135 (39), 78 (11), 77 (10), 63 (10), 44 (17). Anal. Calcd for $\mathrm{C}_{21} \mathrm{H}_{15} \mathrm{NO}_{6}$ 377.0899: C 66.84 H, 4.01; N 3.71. Found: C, 66.79; H, 4.12; N, 3.59.

1,11-Dihydro-3-phenylpyrano[4,3-b]quinolizine-1,11-dione (5a). A mixture of $1.74 \mathrm{~g}$ (5.0 $\mathrm{mmol}$ ) of $4 \mathbf{a}$ and $30 \mathrm{~g}$ of PPA (poly phosphoric acid) was heated under stirring at $100^{\circ} \mathrm{C}$ for 1 hour. The reaction mixture was poured into ice-water. Resulting yellow precipitate was collected by filtration, washed with water, and then dried by air to give yellow crystals. An analytical sample was recrystallized from a mixture of methanol and toluene to give $1.21 \mathrm{~g}$ (4.19 mmol, $84 \%$ ) of yellow needles, mp $256-257^{\circ} \mathrm{C}$. IR (KBr, cm $\left.{ }^{-1}\right): 1751$ (CO), 1654 (CO), 1618, 1542, 1455, 1153, 1023. UV (EtOH) $\lambda$ nm (log $\varepsilon)$ : 443 (4.52), 419 (4.38), 324 (4.31), 302 (4.45), 
282 (4.51). Fluoresence (solid): Ex, $345 \mathrm{~nm}$; Em, $546 \mathrm{~nm}$; RI 0.17. ${ }^{1} \mathrm{H}$ NMR $\left(\mathrm{CDCl}_{3}\right) \delta: 6.47(1 \mathrm{H}$, s, 5-H), 6.70 (1H, s, 4-H), 7.46 (3H, m, phenyl-H), $7.02(1 \mathrm{H}, \mathrm{m}, 8-\mathrm{H}), 7.54(1 \mathrm{H}, \mathrm{m}, 7-\mathrm{H}), 7.89$ (2H, m, phenyl-H), 7.94 (1H, d, J 7.8 Hz, 6-H), 9.22 (1H d, J 6.8 Hz, 9-H). ${ }^{13} \mathrm{C}-\mathrm{NMR}(100 \mathrm{MHz}$, $\left.\mathrm{CDCl}_{3}\right) \delta: 98.38,99.67,115.15,122.54,125.08,125.88,126.84,128.81,129.36,129.45,130.97$, 131.30, 134.34, 146.06, 146.77, 149.12, 155.80, 158.87. Ms:m/z $290\left(\mathrm{M}^{+}+1,23\right), 289\left(\mathrm{M}^{+}, 100\right)$, 233 (16), 232 (13), 205 (15), 204 (59), 105 (13), 77 (13). HRMS (ESI) calcd for $\mathrm{C}_{18} \mathrm{H}_{11} \mathrm{NO}_{3}, \mathrm{~m} /$ z $289.0739\left(\mathrm{M}^{+}\right)$; found, $\mathrm{m} / \mathrm{z} 289.0743$.

1,11-Dihydro-3-(4-methoxy-phenyl)-pyrano[4,3-b]quinolizine-1,11-dione $\quad$ (5b). This compound (0.282 g, $0.884 \mathrm{mmol})$ was prepared in $88 \%$ yield from $(0.378 \mathrm{~g}, 1.0 \mathrm{mmol}) \mathbf{4 b}$ in a manner similar to that described for the synthesis of 5a. An analytical sample was recrystallized from DMF to give yellow needle, mp 214-216 ${ }^{\circ} \mathrm{C}$. IR $\left(\mathrm{KBr}, \mathrm{cm}^{-1}\right): 1735$ (CO), 1637 (CO), 1509, 1457. UV (EtOH) $\lambda \mathrm{nm}(\log \varepsilon): 445$ (4.46), 422 (4.39), 370 (4.12) 343 (4.18), 331 (4.18) 308 (4.28). Fluoresence (solid): Ex, $335 \mathrm{~nm}$; Em, $539 \mathrm{~nm}$; RI 0.02. ${ }^{1} \mathrm{H}$ NMR (DMSO) $\delta: 3.83$ (3H, s, OMe), 6.69 (1H, s, 5-H), 7.07 (1H, s, 4-H), 7.26 (2H, d, J 8.3 Hz, 3', 5'-H), 7.28 (1H, m, 8-H), 7.75 (1H, m, 7-H), $7.81(1 \mathrm{H}, \mathrm{d}, J 8.3 \mathrm{~Hz}, 2$ ', 6'-H), 7.98 (1H, d, J 7.3 Hz, 6-H), 9.03 (1H d, J 7.3 $\mathrm{Hz}, 9-\mathrm{H}) .{ }^{13} \mathrm{C}-\mathrm{NMR}(100 \mathrm{MHz}, \mathrm{DMSO}) \delta:$ 55.48, 95.18, 99.90, 116.26, 120.48, 125.57, 126.99, 135.43, 146.02, 154.87, 156.73, 157.86, 161.41. Ms:m/z $320\left(\mathrm{M}^{+}+1,21\right), 319\left(\mathrm{M}^{+}, 100\right), 306$ (14), 305 (68), 291 (42), 277 (35), 249 (10), 248 (16), 220 (31), 204 (15), 135 (14), 121 (11). HRMS (ESI) calcd for $\mathrm{C}_{19} \mathrm{H}_{13} \mathrm{NO}_{4}, \mathrm{~m} / \mathrm{z} 319.0845\left(\mathrm{M}^{+}\right)$; found, $\mathrm{m} / \mathrm{z} 319.0851$.

\section{References and Notes}

1. (a) Tang, C. W.; Van Slyke S. A. Appl. Phys. Lett. 1987, 51, 913. (b) Tang, C. W.; Van Slyke S. A.; Chen, C. H. J. Appl. Phys. 1989, 65, 3610. (c) Matsuoka, M. J. Soc. Dyers and Colourists 1989, 105, 167. (d) Shirai, K.; Yanagisawa, A.; Takahashi, H.; Fukunishi, K.; Matsuoka, M. Dyes and Pigments 1998, 39, 49. (e) Shirai, K.; Matsuoka, M.; Fukunishi, K. Dyes and Pigments 2000, 47, 107. (f) Seo, H.J.; Park, H, C.; Lee, S. E.; Park, J. W. Current Appl. Phys. 2005, 5, 209. (g) Lee, S. J.; Gallegos, J. R.; Klein, J.; Curtis, M. D.; Kanicki, J. Synth. Metals 2005, 155, 1. (h) Kim, S. K.; Lee, C. J.; Kang, I. N.; Lee, J. H.; Park, J. W. Thin Solid Films 2006, 509, 132. (i) Hirano, K.; Minakata, S.; Komatsu, M. Chem. Lett. 2001, 8. (j) Hirano, K.; Minakata, S.; Komatsu, M. Bull. Chem. Soc. Jpn. 2001, 74, 1567. (k) Yu, J.; Shirota, Y. Chem. Lett. 2002, 984.

2. Mizuyama, N.; Murakami, Y.; Kohra, S.; Ueda, K.; Hiraoka, K.; Nagaoka, J.; Takahashi, K.; Shigemitsu, Y.; Tominaga, Y. J. Heterocycl. Chem. 2007, 44, 115.

3. (a) Tominaga, Y.; Ushirogouchi, A.; Matsuda, Y.; Kobayashi, G. Heterocycles 1977, 8, 193.

(b) Tominaga, Y.; Matsuda, Y.; Kobayashi, G. Chem. Pharm. Bull. 1984, 32, 1665. (c) Tominaga, Y.; Ushirogouchi, A.; Matsuda, Y.; Kobayashi, G. Chem. Pharm. Bull. 1984, 24, 3384. (d) Tominaga, Y.; Ushirogouchi, A.; Matsuda, Y. J. Heterocycl. Chem. 1987, 24, 1557. 
(e) Ram, V. J.; Agarwal, N. Tetrahedron Lett. 2001, 42, 7127. (f) Agarwal, N.; Saxena, A. S.; Farhanullah, Goel, A.; Ram, V. J. Tetrahedron 2002, 58, 8793.

4. Mizuyama, N.; Murakami, Y.; Kohra, S.; Ueda, K.; Hiraoka, K.; Nagaoka, J.; Shigemitsu, Y.; Tominaga, Y. Heterocycles 2006, 68, 1105.

5. Odaka, H.; Okimoto, Y.; Yamada, T.; Okamoto, H.; Kawasaki, M.; Tokuda, Y. Appl. Phys. Lett. 2006, 88, 123501. 